\title{
Finding correlations between hop catalogs and real hoppy character in brewery conditions
}

\author{
Danilo Legisa ${ }^{1,2}{ }^{*}$ and Hernán Mengoni ${ }^{1,2,3}$ \\ Fraternité brewery, Buenos Aires, Argentina \\ 2 Bräu.edu team \\ 3 Labrador Dorado brewery, Buenos Aires, Argentina
}

\author{
Both authors contributed equally to research. \\ * corresponding author: dmlegisa@gmail.com
}

\begin{abstract}
Brewing recipe design is mainly based on brewer's expertise, information available in catalogs and certificates of analysis (CoA's). Hop schedule design and formulation has become an essential topic since hoppy craft beers took the scene. But how accurate is the flavor profile information provided in catalogs? How useful is the chemical composition profile information in CoA's? Besides current research and tons of reported experiences, hops impact is still a mystery, and topics like biotransformation are black-boxes for brewers. In this study, nine single hopped beers were brewed, and a trained panel conducted sensorial beer analysis. Then, to asses hop impact, qualitative and process-related-quantitative beer characteristics were contrasted to find valuable correlations and trends between hop catalogs and final beers. Discrepancies with catalog qualitative data were reported. In addition to what is already described in the literature, here we describe how a-acids, linalool, myrcene, and geraniol (despite the classical use for these compounds) could predict positive and negative hop impact of nine different hop varieties on bitterness, flavor, and aroma, when they are applied in different brewing process steps. Also, with this pipeline we stand the basis of a tool to be improved, available for brewers, to better predict their brews and assess new hop varieties in real-life pilot brewing set ups.
\end{abstract}

Keywords: linalool, geraniol, myrcene, hop flavor, beer, hop oils, bitter acids

\section{Introduction}

Humulus lupulus is possibly the most appreciated raw material in craft brewing nowadays. Belonging to the Rosales order and Cannabaceae family, it shares the family level only with the Cannabis genus. In recent years, $H$. lupulus has been under deep study because of its growing importance driven by general drinker's preference of hoppy beers, possible human health implications (Karabín et al., 2016) and the fact that less was known about the chemistry behind the hoppy impact on highly hopped beers. Research on hop importance in classic beer styles was somehow scarce since the first characterizations from around 1821 (Almaguer et al., 2014) until highly hoppy beers took the craft beer market in the 1990-2000s, with the explosion in the US craft beer scene (Lafontaine and Shellhammer, 2019a). Since then, research has focused not only on the basis of hop impact on flavor and aroma but also on the development of new determination techniques (Kryger et al., 2020) and new cultivars with emerging properties like $H$. neomexicanus taxas (Morcol et al., 2021). In this context, brewers tend to follow commercial trends to achieve more and more hoppy character in beers based on info in catalogs and colleagues' expertise. But sometimes, this information is not clear enough, and experiences are deeply dependent on in-house setups and procedures. Regarding hop chemical composition and its impact on brewing, classic-general division in: resins, essential oils, polyphenols, etc. (waxes, cellulose, amino acids, and so on) was useful 
for recipe formulation until hop bombs took the scene. From today's view, it seems challenging to compile a brief and universal list of chemicals that allows a prediction of aroma impact of hops on a finished beer (Rettberg et al., 2018). Since then, the "black box" of essential oils is being clarified by recent research in order to the better understanding of the chemical basis of hop flavor and aroma (Inui et al., 2013; Nielsen and Shellhammer, 2009; Kishimoto et al., 2006; Fritsch and Schieberle, 2005; Goiris et al., 2002; Lermusieau et al., 2001). It is important to note that "hop deep science" is something "new" since, by the 1950s decade, only two resins were described: humulone and lupulone. Now we know the diversity is much more complex than that (Almaguer et al., 2014). In fact, for the hop oil fraction, around 1,000 different compounds were detected in GC $\times$ GC chromatography assays (Roberts et al., 2004). Recipe formulation for the hoppy character is based on the bitterness to be achieved and the grade of flavor and aroma profile to get. They are based either on iso- $a$-acid for bitterness prediction or total oil content for flavor plus aroma prediction. This approach was demonstrated wrong by empiric and analytics due to $\beta$-acids + humulinones + hulupone and other compounds associated with bitterness perception (Algazzali and Shellhammer, 2016; Maye et al., 2016). In the same way, the use of hop total oil content as a unique indicator for the hoppy character on flavor and aroma is still in debate (Vollmer and Shellhammer, 2016a). Hop catalogs are underexploited by most of brewers; they give us more information than a-acids and total oil content.

In this brewery-based study we aimed to show how qualitative hop catalog information could be affected as result of different ways of process application. Qualitative and quantitative information is accessible by all brewers from hop catalogs, and could be used as a guide to predict the positive and negatives outcomes that a certain hop could impart. Since this study is based on brewery tests, the goal behind this study is also to set a simple pipeline to assess and evaluate single hopped beers for R\&D in any brewery.

\section{Materials and methods}

\section{Wort preparation:}

Recipe was performed at Labrador Dorado Brewery (Caseros, Buenos Aires, Argentina). The following process was designed in Beer Smith software (BeerSmith LLC
2019). Grain bill: Pilsen base (81\%), Munich base (14\%), and Melanoidin (5\%). Water profile: $\mathrm{Ca}^{2+} 85 \mathrm{ppm}, \mathrm{Mg}^{2+}$ $6 \mathrm{ppm}, \mathrm{Na}^{+} 45 \mathrm{ppm}, \mathrm{Cl}^{-} 110 \mathrm{ppm}, \mathrm{SO}_{4}^{2-} 110 \mathrm{ppm}$, and $\mathrm{HCO}^{3-}$ $60 \mathrm{ppm}$. Common wort was prepared and then split in 9 equal parts. The general rule for the 9 assays was $50 \mathrm{l}$ as final volume, which was hopped in the whirlpool (WH) and via dry hopping (DH). Fermentation: initial $19{ }^{\circ} \mathrm{C}$ (Fermentis US05). Cold maturation: $2{ }^{\circ} \mathrm{C}$ until final kegging. Hopping schedule: $\mathrm{WH}$ at $100^{\circ} \mathrm{C}, 20 \mathrm{~min}$., and $\mathrm{DH}$ at $72 \mathrm{hrs}$. post inoculation at $\sim 22^{\circ} \mathrm{C}$. Nine commercial hop varieties were evaluated: Sabro (Yakima Chief-YC), Galaxy (Barth Haas-BH), Lemondrop (Hopsteiner-HS), Centennial (YC), Chinook (YC), Ekuanot (YC), Amarillo (YC), Citra (YC), Comet (YC). Hop schedule is shown in Table 1. Sensory analysis was conducted and hop contributions to final beer was calculated.

Table 1 Hop additions for each single hop beer.

\begin{tabular}{|c|c|c|c|c|}
\hline HOP & Brand & Whirlpool $(\mathrm{g} / \mathrm{l})$ & Dry Hop $(\mathrm{g} / \mathrm{l})$ & Total $(\mathrm{g} / \mathrm{l})$ \\
\hline Sabro & Yakima Chief & 1.5 & 3.0 & 4.5 \\
\hline Galaxy & Bart Haas & 5.0 & 6.0 & 11.0 \\
\hline Lemondrop & Hopsteiner & 3.0 & 3.0 & 6.0 \\
\hline Centennial & Yakima Chief & 2.0 & 3.0 & 5.0 \\
\hline Chinook & Yakima Chief & 2.5 & 2.5 & 5.0 \\
\hline Ekuanot & Yakima Chief & 5.0 & 5.0 & 10.0 \\
\hline Amarillo & Yakima Chief & 4.0 & 3.5 & 7.5 \\
\hline Citra & Yakima Chief & 1.0 & 1.0 & 2.0 \\
\hline Comet & Yakima Chief & 4.0 & 4.0 & 8.0 \\
\hline
\end{tabular}

\section{Tasting panel and dataset constructing:}

An $\mathrm{N}=24$ person tasting panel was recruited, 7/24 graded-BJCP (Beer Judge Certificating Programme), and 4/24 women. All of them trained homebrewers or pro-brewers. All beers were challenged in a blind tasting design (tasters did not know what beer they evaluated each time). Variables recorded were taken from literature: citric, earthy, cream/candy, vegetal, wood, spicy, fruit, mint, floral, tropical fruit, resinous, skunk, onion, tomato stem, cheese, persistence, metallic, balsamic and, aroma, flavor, total hoppy character, bitterness intensity, bitterness persistence, astringency and harsh. Evaluations were conducted in a 0 to 6 score system and general calibration was done prior to tasting session. Datasets were constructed with the above listed data and information from catalogs: $\% \alpha$-acids, $\% \beta$-acids, $\alpha / \beta$ ratio, $\%$ cohumulone, total oils (ml/100 g), \% linalool, \% geraniol, \% myrcene. Since we want to characterize hop impact from a consumers point of view and to assess the aroma/flavor compounds, AROMA term is used as synonymous to odor 
and FLAVOR as the combination of: aromatics, tastes and chemical feeling factors (Meilgaard et al., 2016). Data acquisition from catalogs followed each brand criteria although all values were normalized to be compared in this report. Average values for selected variables were calculated to construct spider graphs, linear paired regressions, correlation matrix and PCA.

Specific hop characteristics were taken from manufacturer's catalogs: hop aroma/flavor qualitative characteristics and chemical composition. Calculations were made to determine additions during brewing process. Hop aroma and flavor total score were obtained by adding all respective individual scores. Total hoppy character was then obtained, adding previous scores. From here, added-during-process calculated components are marked by "add-" and catalog info by "cat-". For each variable formula were done according to:

$$
\begin{aligned}
& \text { I. } \quad \alpha \beta \text { ratio }=\frac{\%_{\alpha}}{\%_{\beta}} \\
& \text { II. add }-c_{\text {HEO } / W H}=\%_{H E O} * c_{\text {hop } / W H^{i}} \\
& \text { III. add }-c_{H E O / D H}=\%_{H E O} * c_{\text {hop } / D H^{\prime}} \\
& \text { IV. } \operatorname{add}-c_{H E O}=c_{\text {hop }} * \%_{H E O} \text {; } \\
& \text { V. } \quad \text { add }-c_{\alpha / W H}=\%_{\alpha} * \frac{c_{h o p / W H}}{100} \text {; } \\
& \text { VI. } \quad \text { add }-c_{\alpha / D H}=\%_{\alpha} * \frac{c_{h o p / D H}}{100} \text {; } \\
& \text { VII. add }-c_{\alpha}=c_{\text {hop }} * \% \text {; } \\
& \text { VIII. add }-c_{\beta}=c_{\text {hop }} * \%_{\beta} \text {; } \\
& \text { IX. } \quad \text { add }-c_{\text {coh }}=\text { add }-c_{\alpha} * \%_{c o h} * 1000 \\
& \text { X. } \quad \text { add }-c_{\text {lin } / \mathrm{WH}}=\operatorname{add}-\mathrm{c}_{\mathrm{HEO} / \mathrm{WH}} * \%_{\operatorname{lin}} * 1000 \\
& \text { XI. } \quad \text { add }-\mathrm{c}_{\operatorname{lin} / \mathrm{DH}}=\text { add }-\mathrm{c}_{\mathrm{HEO} / \mathrm{DH}} * \%_{\operatorname{lin}} * 1000 \\
& \text { XII. } \quad \text { add- } \mathrm{c}_{\text {lin }}=\text { add- } \mathrm{c}_{\text {HEO }} * \%_{\operatorname{lin}} * 1000 \\
& \text { XIII. add- } \mathrm{c}_{\mathrm{ger} / \mathrm{wH}}=\text { add- } \mathrm{c}_{\mathrm{HEO} / \mathrm{wH}} * \%_{\text {ger }} * 1000 \\
& \text { XIV. } \quad \text { add }-c_{\text {ger } / \mathrm{DH}}=\operatorname{add}-\mathrm{c}_{\mathrm{HEO} / \mathrm{DH}} * \%_{\mathrm{ger}} * 1000 \\
& \text { XV. } \quad \text { add }-\mathrm{c}_{\text {ger }}=\text { add- } \mathrm{c}_{\text {HEO }} * \%_{\text {ger }} * 1000 \\
& \text { XVI. } \quad \text { add- } \mathrm{c}_{\mathrm{myr} / \mathrm{WH}}=\mathrm{add}-\mathrm{c}_{\mathrm{HEO} / \mathrm{WH}} * \%_{\mathrm{myr}} * 1000 \\
& \text { XVII. add- } \mathrm{c}_{\mathrm{myr} / \mathrm{DH}}=\text { add- } \mathrm{c}_{\mathrm{HEO} / \mathrm{DH}} * \%_{\mathrm{myr}} * 1000 \\
& \text { XVIII. add }-\mathrm{c}_{\mathrm{myr}}=\operatorname{add}-\mathrm{c}_{\mathrm{HEO}} * \%_{\mathrm{myr}} * 1000
\end{aligned}
$$

, where

$\%_{\alpha} \quad$ is a weight percentage of $\alpha$-bitter acids; $\%_{\beta} \quad$ is a weight percentage of $\beta$-bitter acids; add- $\mathrm{C}_{\mathrm{HEO} / \mathrm{wH}}[\mathrm{ml} / \mathrm{l}]$ is a concentration of hop essential oils (HEO) in a hop dose added to whirlpool;

$\%_{\text {HEO }} \quad$ is a relative percentage $(\mathrm{v} / \mathrm{w})$ of $\mathrm{HEO}$ in the used hop;

$\mathrm{c}_{\text {hop/wH }}[\mathrm{g} / \mathrm{l}] \quad$ is a dose of hop in a whirlpool;

add- $\mathrm{c}_{\mathrm{HEO} / \mathrm{DH}}[\mathrm{ml} / \mathrm{l}]$ is a concentration of HEO in a hop dose added via dry hopping;

$$
\begin{aligned}
& \mathrm{C}_{\text {hop/DH }}[\mathrm{g} / \mathrm{l}] \\
& \mathrm{c}_{\text {hop }}[\mathrm{g} / \mathrm{l}] \\
& \text { add }-\mathrm{c}_{\mathrm{HEO}}[\mathrm{ml} / \mathrm{l}] \quad \text { is a theoretical amount of HEO added } \\
& \text { add- } c_{\alpha / w}[\mathrm{~g} / \mathrm{l}] \\
& \text { add- } \mathrm{c}_{\alpha / \mathrm{DH}}[\mathrm{g} / \mathrm{l}] \\
& \text { add- } \mathrm{c}_{\alpha}[\mathrm{g} / \mathrm{l}] \\
& \text { add- } c_{\beta}[\mathrm{g} / \mathrm{l}] \\
& \text { add- } \mathrm{c}_{\mathrm{coh}}[\mathrm{mg} / \mathrm{l}] \\
& \% \mathrm{c}_{\mathrm{coh}} \\
& \operatorname{add}-c_{\operatorname{lin} / W H}[\mu \mathrm{l} / \mathrm{l}] \\
& \%_{\text {lin }} \\
& \text { add-c } c_{\operatorname{lin} / \mathrm{DH}}[\mu \mathrm{l} / \mathrm{l}] \\
& \operatorname{add}-c_{\operatorname{lin}}[\mu \mathrm{l} / \mathrm{l}] \\
& \text { add- } c_{\text {ger } / w}[\mu \mathrm{l} / \mathrm{l}] \\
& \%_{\text {ger }} \\
& \text { add- } \mathrm{c}_{\mathrm{ger} / \mathrm{DH}}[\mu \mathrm{l} / \mathrm{l}] \\
& \text { add- } \mathrm{c}_{\text {ger }}[\mu \mathrm{l} / \mathrm{l}] \\
& \text { add- } c_{\mathrm{myr} / \mathrm{w}}[\mu \mathrm{l} / \mathrm{l}] \\
& \%_{\text {myr }} \\
& \text { add }-c_{\text {myr/DH }}[\mu \mathrm{l} / \mathrm{l}] \\
& \text { add }-c_{\text {myr }}[\mu \mathrm{l} / \mathrm{l}] \\
& \text { during brewing process; } \\
& \text { is a hop dose added via dry hopping; } \\
& \text { is a total hop dose in a wort; } \\
& \text { a hop dose added in whirlpool; } \\
& \text { is a concentration of } \alpha \text {-bitter acids in } \\
& \text { a hop dose added via dry hopping; } \\
& \text { is a theoretical concentration of } \\
& \alpha \text {-bitter acids added during brewing } \\
& \text { process; } \\
& \text { is a theoretical concentration of } \\
& \beta \text {-bitter acids added during brewing } \\
& \text { process; } \\
& \text { is a theoretical concentration of } \\
& \text { cohumulone added during brewing } \\
& \text { process; } \\
& \text { is a concentration of linalool in a hop } \\
& \text { is a concentration of geraniol in a hop }
\end{aligned}
$$

\section{is a concentration of geraniol in a hop}

\section{Statistical analysis:}

Normal distribution was checked for all variables obtained by the tasting panel using Shapiro test. Paired linear regressions were conducted in Microsoft Excel (Figure 2). PCA-Biplots (Figure 3, 5) and correlation analysis (Figure 4) were conducted in R software (R-Core-Team 2020). For PCA analysis, relevant variables were select- 
ed to contrast catalog info and beer additions. Grouping (ellipses on PCA Figure 3,5) were defined according to the Euclidean distance matrix and UPGMA clustering (Unweighted Pair Group Method with Arithmetic Mean).

\section{Results}

Single hopped beers recorded characteristics vs. catalog information

Through the beer tasting panel, a characteristic profile for each single hopped beer was recorded. Comparative spider graphics (Figure 1) show qualitative differences between recorded hop profiles on each beer vs. those provided by manufacturers. Interestingly for some cases (Figure $1 \mathrm{~A}, \mathrm{D}$, and G Sabro, Centennial, and Amarillo) the expected and obtained profiles are similar but "diminished" in total value intensity, while for Lemondrop and Ekuanot, expected and obtained profiles were very similar (Figure $1 \mathrm{C}$ and F). Surprisingly, differences are evident for other cases like Galaxy, Chinook, Citra, and Comet (Figure 1 B, E, H and I). PCA (Figure 3) analysis based on the same dataset (qualitative manufacturer's

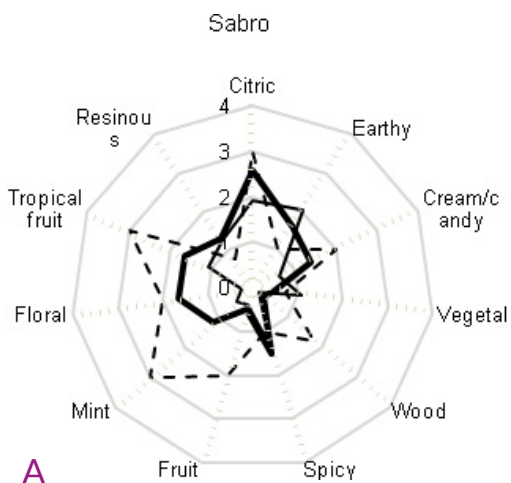

Centennial

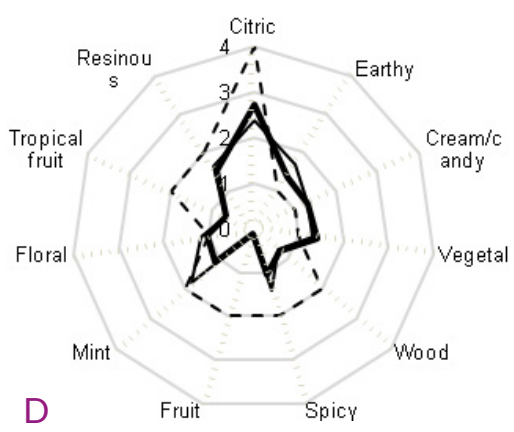

Amarillo

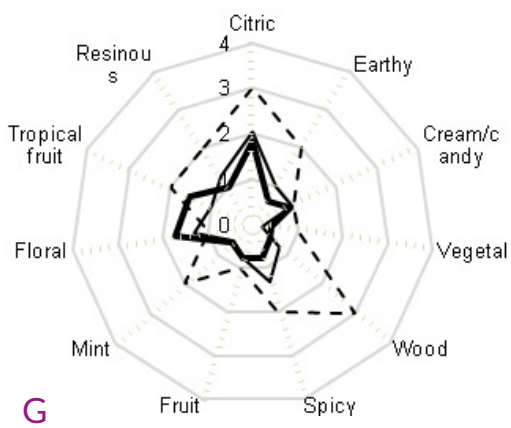

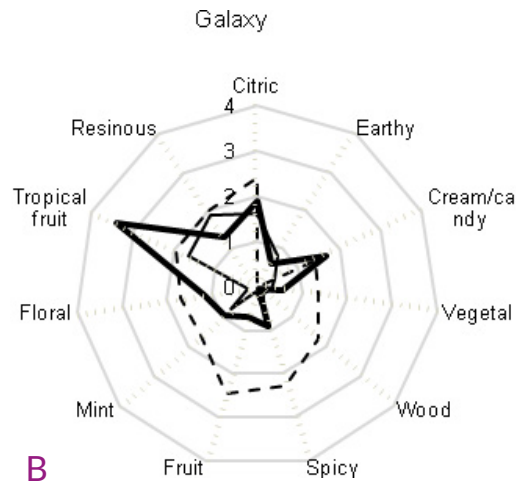

Chinook

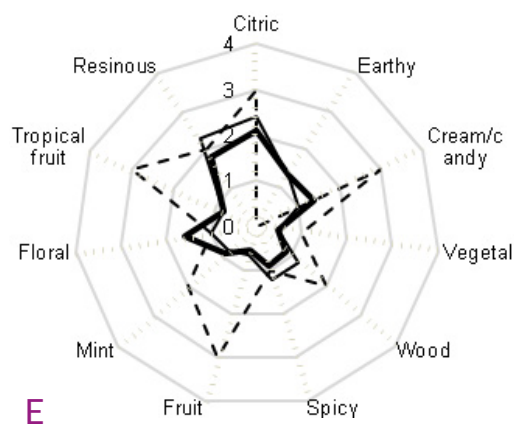

Citra

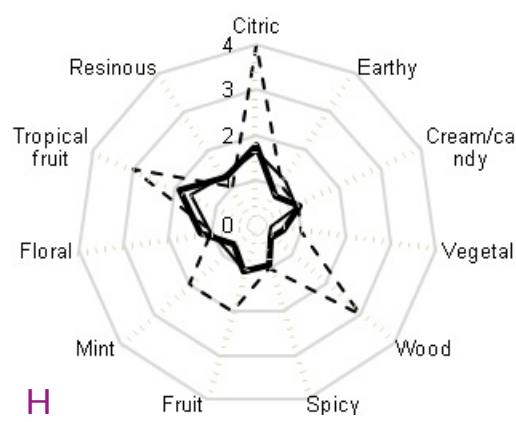

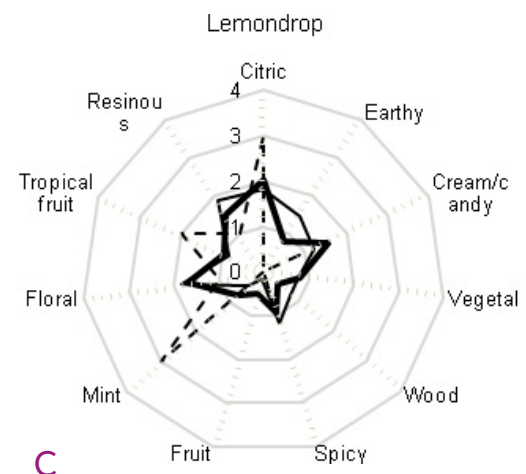

Ekuanot

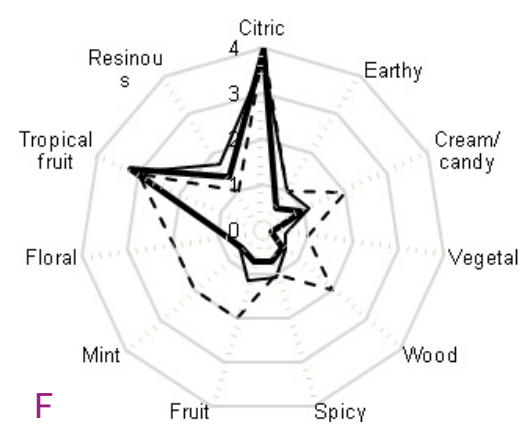

Comet

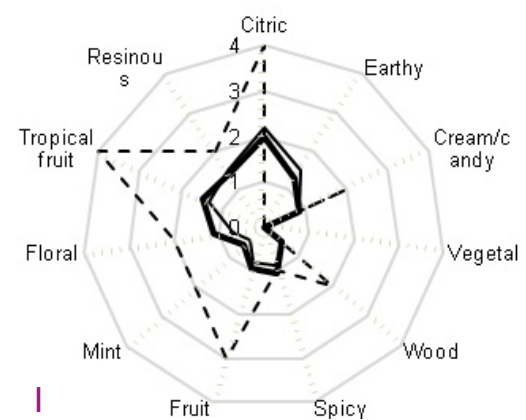

References

Aroma: Flavor: _ Manufacturer information (hop cones): - - - -

Figure 1 Flavor profiles recorded for each single hopped beer for this assay and manufacturer's catalog information corresponding to the sensory attributes of hop cones. Strong lines: aroma, thin lines: flavor, dotted lines: catalog information. 

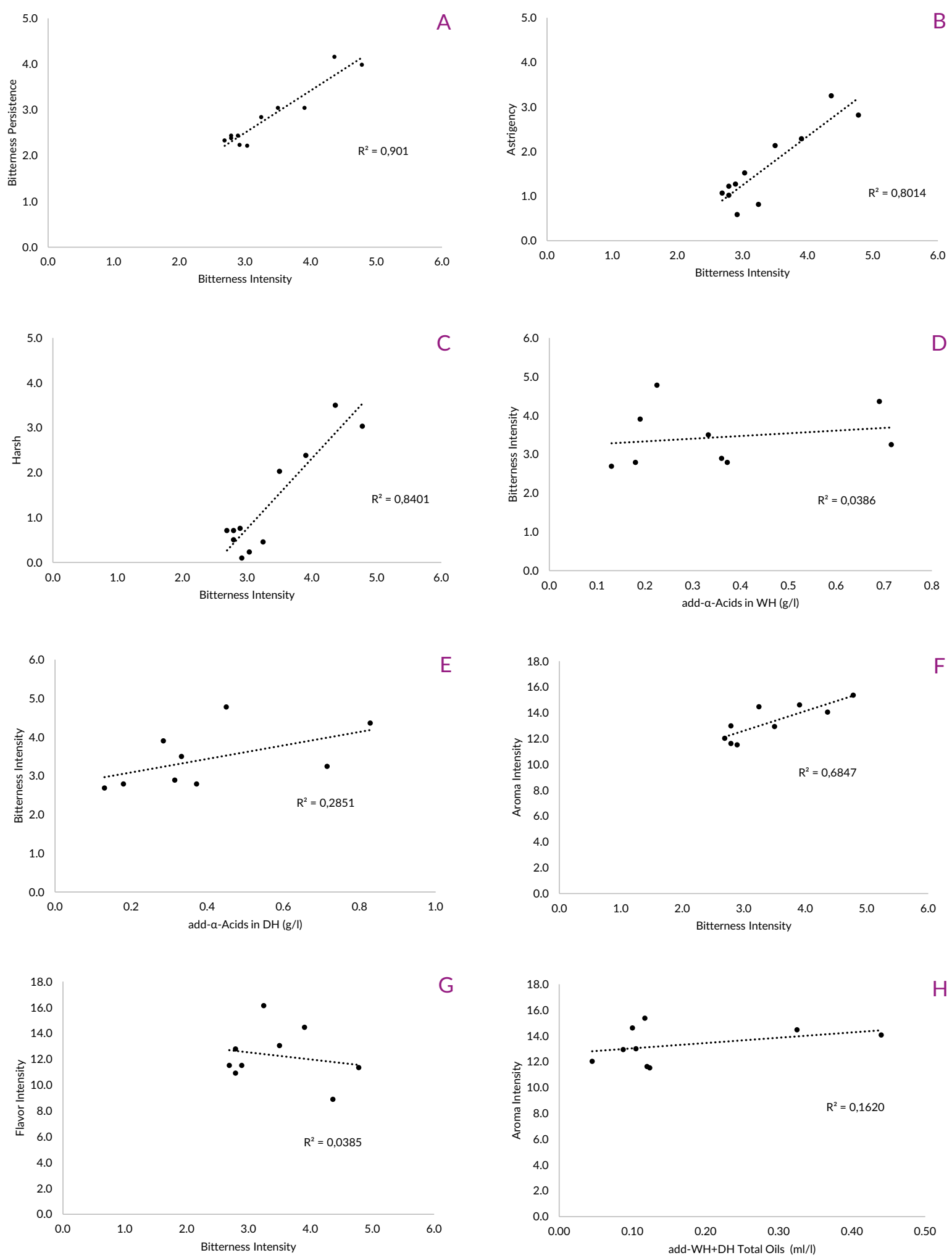

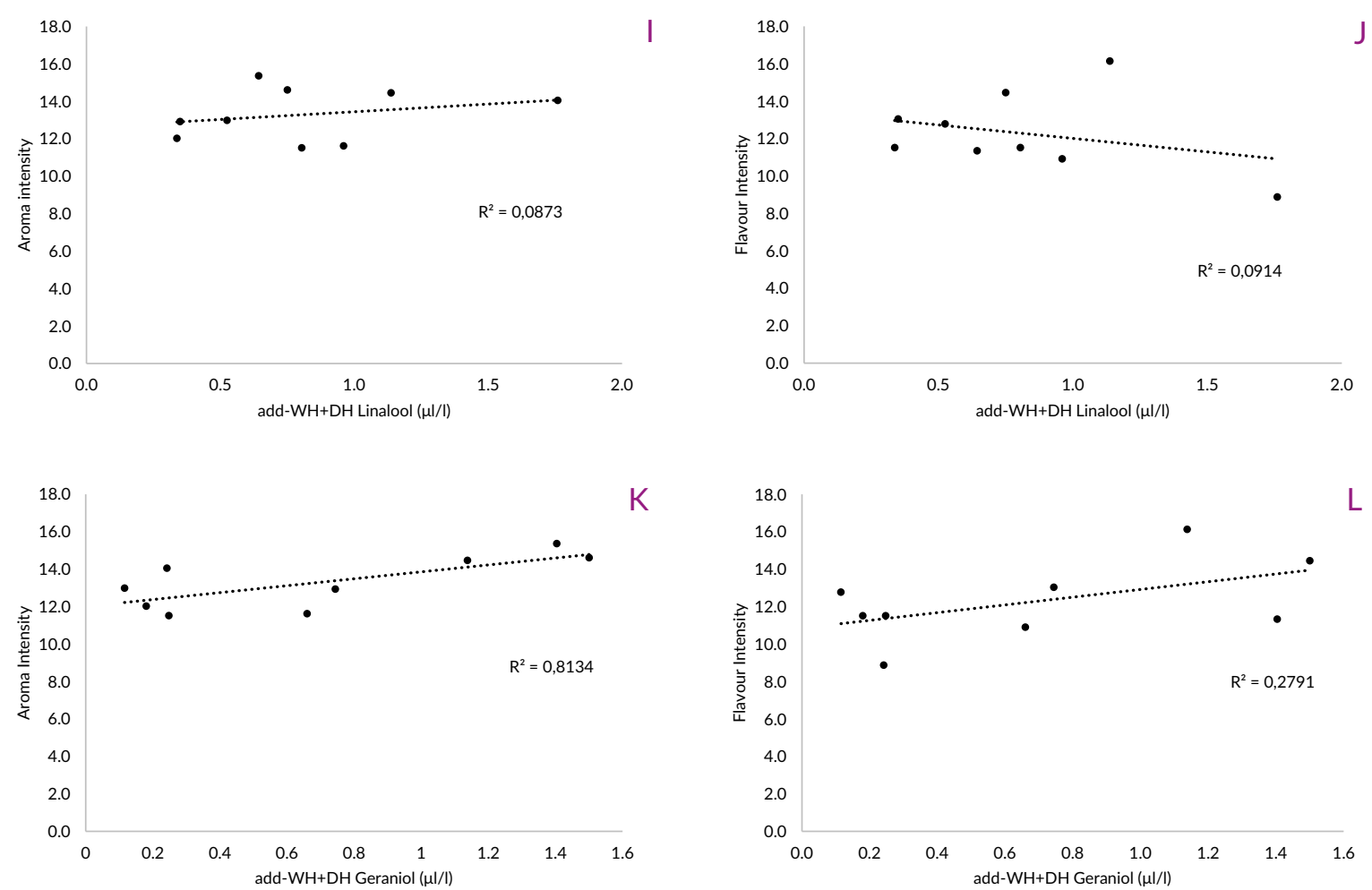

Figure 2 Linear regression plots for selected paired variable comparisons. $R^{2}$ values are showed in each plot.

hop-profile information vs. beer tasting panel results) shows us a global idea contrasting single hopped beers and catalog-based characters in which assayed beers and catalog-beers did not group together a single time. It is important to note in Figure 3 that almost all catalogs-individuals grouped in the external graphic region while assayed-individuals grouped almost together close to the axis origin, showing less hop-intensity. Besides this,

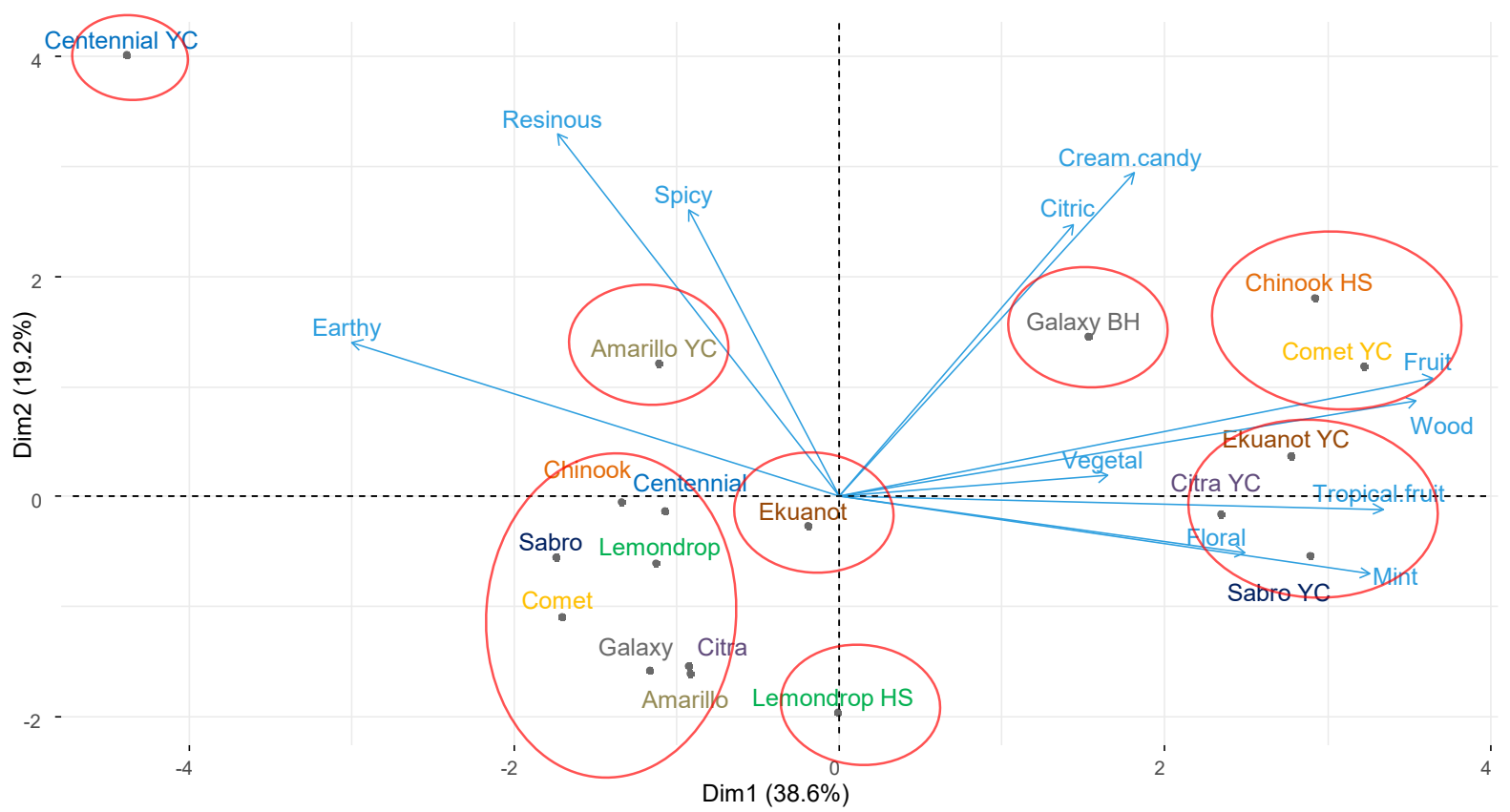

Figure 3 Principal Component Analysis bi-plot for qualitative manufacturer's hop-profile information vs. beer tasting panel results. Each hop catalog-based individual is marked by producer's suffix code: HS (Hopsteiner); BH (Bart Haas) and YC (Yakima Chief). Groupings showed by red circles are defined by UPGMA. 
a pronounced hoppy character was recorded by tasting panel. Further, PCA analyzing catalog information about chemical hop composition and aroma/flavor compounds added-during-process was performed (see below and Figure 4 and 5). For each intra-hop-variety, statistical analysis on Euclidean distances (based on dissimilarity matrix) for catalog vs. assayed beers, resulted in the following ranking (best to worst): Ekuanot, Lemondrop, Amarillo, Galaxy, Centennial, Sabro, Citra, Chinook, and Comet, coincident with spider graphs.

\section{Hoppy character and estimated impact on beer}

Chemical hop composition data, extracted from hop producer's catalogs, was used to estimate addition of hop related compounds during brewing process. A correlation matrix plot is shown in Figure 4, involving all variables taken for this analysis: those extracted from catalogs, those calculated, and the hoppy features recorded by the tasting panel. In Figure 2 selected linear regressions are shown. As expected, a "bitterness-cluster" (astringency, bitterness persistence, bitterness intensity, and harshness) showed a high and positive correlation. As well as bitterness intensity correlated positively with inferred $\alpha$-acids added during DH. Aroma intensity also correlated positively with bitterness intensity (Figure 2F), a clear trend was obtained despite the $\mathrm{R}^{2}$ value. On the other hand, flavor intensity didn't show any trend or correlation with bitterness intensity. Aroma intensity positively correlated with total oils added in WH or DH, and linalool added during the same process steps, although it recorded just a slight trend for these correlations (Figure 2). On the other hand, flavor intensity seems to have no correlation with add-linalool added during $\mathrm{WH}$ and/or $\mathrm{DH}$, but it had a clear positive trend for add-geraniol added dur-

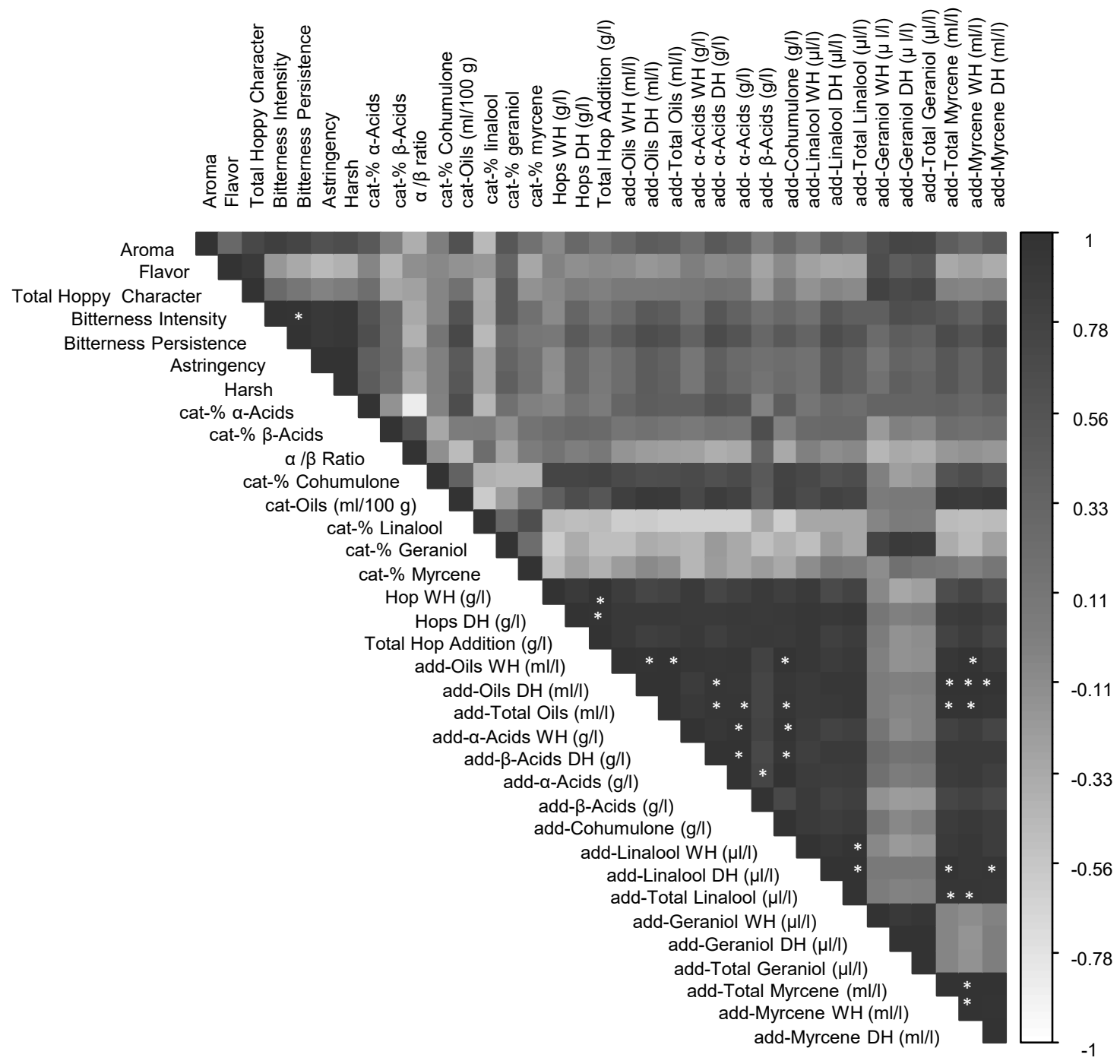

Figure 4 Correlation matrix plot for sensory recorded traits, catalog information and process related composition. Greyscale represents correlation factor value from -1 (white) to 1 (black). See materials and methods for further info. Asterisks show significant correlations. 
ing the same process steps. Myrcene in terms of hop aroma or hop flavor showed the same pattern as recorded for linalool: positive correlation with aroma either in $\mathrm{WH}$ and/or DH, but no with flavor. Current results do not allow discerning between differential impacts of linalool/ myrcene in whirlpool compared to dry hop. A sub-group of no redundant variables were selected for PCA analysis to assess aroma/flavor compounds added during the process and tasting panel results analyzing all variables at once. As it is in the previous PCA analysis, results are dependent on the current dataset, and they should be analyzed on this basis. In this instance, there is a clear trend for variables to group in two general directions (light blue vectors) coincident with axis/Dim, first: Flavor, Total Hoppy Character, add-Geraniol content, Bitterness, and Harshness, and second: add- $\alpha$-Acids, add-Total Oils, add-Myrcene, add-Cohumulones, add-Linalool, add$\alpha$-Acids and Total Hop added. All variables are present as harmonious in terms of impact on variability regardless of their cluster in orientation. It is important to note that most of these variables formed a $<90^{\circ}$ angle between each other, showing some degree of correlation. This trend could also be checked in Figure 4. In terms of hops, Sabro and Centennial grouped far from the origin correlating with the first variables group zone while Ekuanot and Galaxy showed a significant correlation with second group Flavor, Total Hoppy Character, add-Geraniol content, Aroma, and Bitterness. Because of the nature of the method, hop varieties that recorded low hoppy values by the tasting panel (Amarillo, Comet, Lemondrop, Citra, and Chinook), grouped in the same cluster but showed corresponding tendencies with one of the two variable main directions mentioned above.

\section{Discussion}

Hop growers flavor wheels in catalogs are often based on sensorial analysis of cone scrutiny, pellet tea, or even "rub and sniff" fresh cones, and maybe this does not reflect individual brewing practices including craft brewing processes. Also, pilot hop-characterizations are usually performed based on pilsner recipes, in which a small hop addition could be of high impact. Hop oil chemical composition is highly dependent on variety, vantage, nutrient, growing conditions (Gahr and Forster, 2014), hop cone ripening time (Lafontaine et al., 2019; Sharp et al., 2014), kilning conditions (Lafontaine, Hauser, et al., 2018), storage conditions (Tressl et al., 1978) crop year, harvest date (Bailey, 2009), the terroir (Van Holle et al., 2017, 2021); and everything that happens from harvest to brewing. Hop impact during brewing and fermenta-

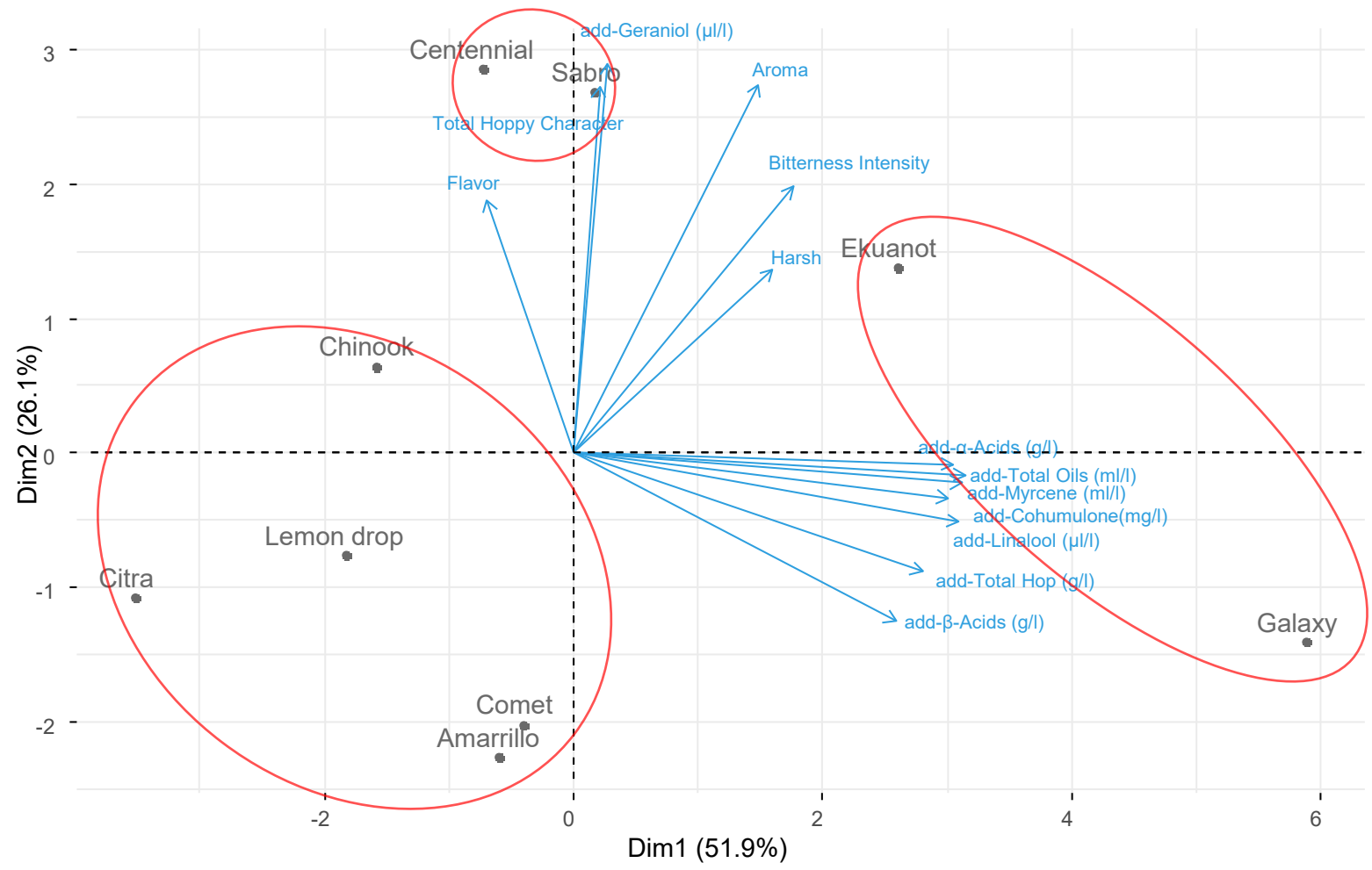

Figure 5 Principal Component Analysis biplot for hop character recorded and process related composition. Grouping showed by red circles was defined by UPGMA. 
tion is still treated as a "black box", bypassing all possible interactions between hop and other raw materials. At the same time, controlling variables along the essay (grist malt, $\mathrm{T}^{\circ}$, hop dosing, etc.) have allowed us to considerate separately real hop impact from the eyes (or palate) of brewers and tasters, who are the final user of the hop-product.

As it is shown in this report, although a hoppy character was successfully obtained, discrepancies between info provided by manufacturers and sensory panel were recorded. Some discrepancies are evident in Figure 1 and detected by Euclidean distances analysis and PCA (Figure 3), showing that info provided by manufacturers not always represents what hop yields at final beer due to the complex mechanism behind the transfer of the hop profile to the beer. In our system, as expected, bitterness persistence, astringency, and harshness were highly correlated with sensorial bitterness intensity. Higher bitterness leads to low-quality bitter taste. Oladokun et al. $(2016,2017)$ have reported that the more bitterness intensity, the more astringent, lingering, and less rounded was the perceived bitterness. Poor bitterness quality is usually related to the quantity of polyphenols and their polymerization degree (Lesschaeve and Noble, 2005) unfortunately, polyphenol content in hops catalogs is not available, although it can be assumed that the more hops we add, the more polyphenols added too. The same occurs to humulinones negative impact on bitterness, as $\alpha$-acids are added, humulinones too. Humulinones are unstable at higher temperatures (Lewis and Young, 2002; Ferreira et al., 2018) and maybe this explains the higher impact of add- $\alpha$-acids in DH for bitterness intensity (Figure 2). Finally, \% cohumulone added didn't show correlation with any bitterness trait. It is known that despite the bad reputation cohumulone has about bitterness quality, there is no real evidence on that (Ting and Ryder, 2017). Analyzing the hop's non-bitter side, the first intra-catalog correlation is: the higher $\alpha$-acids for a variety, higher total oils are detected. Then, for hop additions to achieve positive impact will bring extra bitterness too. We detected a positive correlation between aroma and bitterness intensity and decreasing for aroma vs. bitterness persistence, astringency, or harshness, previously supported in literature (Oladokun et al., 2017). Total oil conceived as indicator of hop aroma intensity is still being discussed (Lafontaine, Pereira, et al. 2018; Vollmer and Shellhammer, 2016b). The more total oils are added in WH and DH; our tasting panel registered the more aroma intensity. Although we recorded higher association between aroma and total oils added during DH. Again, to achieve better aroma impact, to use the total oil amount as an indicator would drive to better results. A correlation between flavor intensity and total oils was not seen, but a trend was recorded for aroma intensity vs. add-total oils in $\mathrm{WH}$ and $\mathrm{DH}$.

Regarding the oils found in catalogs (linalool, geraniol and myrcene), linalool is considered as a universal hoppy impact indicator, or more specifically as an aroma intensity indicator (Biendl et al., 2015). As expected, add-linalool showed a positive impact in hop aroma intensity when added during WH and/or DH. The same findings were reported by (Hanke et al., 2008). On the other hand, linalool showed no impact on hop flavor, disregarding if it is used in $\mathrm{WH}$ or $\mathrm{DH}$. The same pattern was recorded for add-myrcene. $\beta$-Myrcene rich varieties also contain high ester concentration (Naya and Kotake, 1972), which could lead us to think of myrcene content as a predictor of hop aroma impact (due to esters besides myrcene itself), as it was recorded in the present assay. Also, some esters were recently characterized as "survivable" compounds, so this line could be even more interesting given that, we can expect that myrcene will be volatilized, and esters could persist (Tielkemeier, 2020; Lafontaine and Shellhammer, 2019b). Our results do not clearly differentiate add-myrcene impact in WH or DH. Further research should be done to better infer if, given the volatile nature of myrcene (more important during WH than DH), we could think of ester contribution to aroma indirectly inferred by the myrcene amount added. In the other hand, our tasting panel characterized the more myrcene-containing varieties used here (Galaxy, Ekuanot and Sabro) clustering not necessarily related to myrcene direct impact: green, herbal, and resinous flavor. So myrcene related flavors, sometimes no desired, could be neglected knowing that esters could be present when high myrcene amounts are reported. At PCA Biplot (Figure 5) add-geraniol showed to better correlate with desired hoppy characters: flavor, total hoppy character, and aroma, while add-myrcene and add-linalool showed good correlation mainly with aroma. Add-geraniol showed positive correlation for aroma and flavor (Figure 2) when it was used either in DH and/or WH. For geraniol, diverse transfer rates were reported by Dresel et al. (2015), and could explain the poor values for slope and $\mathrm{R}^{2}$ at Figure 2, however the trend is still positive. In line with these results Lafontaine, Pereira, et al. (2018), found a significant positive correlation between overall hop aroma intensity and geraniol in dry-hopped beers. It is important to point that geraniol is a well-known substrate for biotransformation (Takoi et al., 2010) so its impact could be also due to potential biotransformation occurring in the background (or into the black box). In addition, Takoi et al. (2016) also proposed that geraniol and linalool could act synergistically between them and 
with some volatile thiols, i.e.: 4MSP (4-methyl-4-sulfanylpentan-2-one), and also, linalool and geraniol were also characterized as "survivable" compounds in a recent Yakima Chief research (Tielkemeier, 2020), then, a major impact hoppy beer could be hypothesized.

\section{Conclusion}

This pipeline results from consistent records obtained from the blind tasting, where some of these results were supported by literature. Nevertheless, not all aspects behind this tool have been studied and this needs to be carried out in future experiments. Across the study, we recorded clear discrepancies between hop profile found in the catalogs and the obtained beers. Also we found interesting insights between sensorial profiles in the pre-pilot scale (50 l) and the information extracted from the catalogs: added $\alpha$-acids yield in higher and undesired bitterness even out of the hot side, linalool and myrcene seem to be good indicators for aroma, despite myrcene reputation itself, but no for flavor, and geraniol as good indicator for aroma and flavor. The idea of using these predictors relies on its practicality and the direct improvement of hop utilization. For future directions, lab support is required to achieve precise data on hop composition used at the brewery. This would open opportunities for new indicators like esters and thiols.

This report proposes a simple tool with a simple pipeline to assess hop quality for microbreweries. Nevertheless, further research is needed to keep untangling the principles and mechanisms within the black box of hop use and biotransformation, concepts pronounced by many brewers but barely understood.

\section{Acknowledgments}

We want to thank "Cerveceros Ribera Norte", our brewing club at Buenos Aires, Argentina for participating in the big wort day and in the further tasting panel. Also, our thanks go to Maria Sol Perez Aguirreburualde and Martin Westerdahl for the critical manuscript review.

\section{References}

Algazzali, V, Shellhammer, T. (2016). Bitterness Intensity of Oxidized Hop Acids: Humulinones and Hulupones. Journal of the American Society of Brewing Chemists, 74(1),36-43. https://doi.org/10.1094/ASBCJ-2016-1130-01

Almaguer, C., Schönberger, Ch., Gastl, M., Arendt, E.K., Becker, T. (2014). Humulus lupulus - a Story That Begs to Be Told. A Review." Journal of the Institute of Brewing, 120(4), 289-314. https://doi.org/10.1002/jib.160

Bailey, B., Schönberger, Ch., Drexler, G., Gahr, A., Newman, R., Pöschl, M.,
Geiger, E. (2009). The Influence of Hop Harvest Date on Hop Aroma in Dry-Hopped Beers. MBAA Technical Quarterly, 46(2), 3-6. https:// doi.org/10.1094/tq-46-2-0409-01

BeerSmith LLC (2019). Beersmith 2. BeerSmith ${ }^{\mathrm{TM}}$ Home Brewing Software. Retrieved from http://beersmith.com/

Biendl, M., Engelhard, B., Forster, A., Gahr, A., Lutz, K., Müller-Auffermann, A., Mitter, W., Schmidt, R., Schonberger, C. (2015). Hops Their Cultivation, Composition and Usage. Nuremberg: Fachverlag Hans Carl, pp. 333. ISBN 978-3-418-00900-1

Dresel, M., Praet, T., Van Opstaele, F., A. Van Holle, A., Naudts, D., De Keukeleire, D., L. De Cooman, L., Aerts, G. (2015). Comparison of the Analytical Profiles of Volatiles in Single-Hopped Worts and Beers as a Function of the Hop Variety. BrewingScience, 68(1-2), 8-28.

Ferreira, C.S., de Chanvalon, E.T., Bodart, E., Collin, S. (2018). Why Humulinones Are Key Bitter Constituents Only After Dry Hopping: Comparison With Other Belgian Styles. Journal of the American Society of Brewing Chemists, 76(4), 236-246. https://doi.org/10.1080/0361 0470.2018 .1503925

Fritsch, H.T., Schieberle, P. (2005). Identification Based on Quantitative Measurements and Aroma Recombination of the Character Impact Odorants in a Bavarian Pilsner-Type Beer. Journal of Agricultural and Food Chemistry, 53(19), 7544-7551. https://doi.org/10.1021/ jf051167k

Gahr, A., Forster, A. (2014). A Comparison of the Analytical and Brewing Chracteristics of Cascade and Comet Hop Varieties as Grown in Yakima (USA) and Hallertau (Germany). Brewing Science, 67(11-12), 137-148. https://doi.org/10.23763/BrSc14-31forster

Goiris, K., Ridder, M., Rouck, G., Boeykens, A., Opstaele, F., Aerts, G., Cooman, L., Keukeleire, D. (2002). The Oxygenated Sesquiterpenoid Fraction of Hops in Relation to the Spicy Hop Character of Beer. Journal of the Institute of Brewing, 108(1), 86-93. https://doi. org/10.1002/j.2050-0416.2002.tb00129.x

Hanke, S., Herrmann, S., Rückerl, M., Schönberger, C., Back, W. (2008). Hop Volatile Compounds (Part II): Transfer Rates of Hop Compounds from Hop Pellets to Wort and Beer. Brewing Science, 61(7-8), 135139.

Van Holle, A., Van Landschoot, A., Roldán-Ruiz, I., Naudts, D., De Keukeleire, D. (2017). The Brewing Value of Amarillo Hops (Humulus lupulus L.) Grown in Northwestern USA: A Preliminary Study of Terroir Significance. Journal of the Institute of Brewing, 123(3), 312-318. https://doi.org/10.1002/jib.433

Van Holle, A., Muylle, H., Haesaert, G., Naudts, D., De Keukeleire, D., Roldán-Ruiz, I., Van Landschoot, A. (2021). Relevance of Hop Terroir for Beer Flavour. Journal of the Institute of Brewing, 127(3), 238247. https://doi.org/10.1002/jib.648

Inui, T., Tsuchiya, F., Ishimaru, M., Oka, K., Komura, H. (2013). Different Beers with Different Hops. Relevant Compounds for Their Aroma Characteristics. Journal of Agricultural and Food Chemistry, 61(20), 4758-4764. https://doi.org/10.1021/jf3053737

Kishimoto, T., Wanikawa, A., Kono, K., Shibata, K. (2006). Comparison of the Odor-Active Compounds in Unhopped Beer and Beers Hopped with Different Hop Varieties. Journal of Agricultural and Food Chemistry, 54(23), 8855-8861. https://doi.org/10.1021/jf061342c

Kryger, S., Colquhoun, T.A., Sarnoski, P.J., Pearson, B.J., Andrew, J., Keene, S.A., Odabasi, A.Z., Baker, S.M., Sims, C. (2020). Sensory and Compositional Analysis of Florida-Grown Hops. MBAA Technical Quarterly, 57(3), 134-141. https://doi.org/10.1094/tq-57-3-0731-01

Karabín, M., Hudcová, T., Jelínek, L., Dostálek, P. (2016). Biologically Active Compounds from Hops and Prospects for Their Use. Comprehensive Reviews in Food Science and Food Safety,15(3), 542-67. https://doi. org/10.1111/1541-4337.12201

Lafontaine, S.R., Hauser, D.G., Foster, R., Donaldson, J., Gamache, D., Shell- 
hammer, T.H. (2018). Impact of Kiln Temperatures on the Aroma and Enzymatic Potential of Hops during Dry-Hopping. n EBC Symposium on "Recent Advances in Hop Science", Nuremberg, 2018.

Lafontaine, S.R., Pereira, C., Vollmer, D.M., Shellhammer, T.H. (2018). The Effectiveness of Hop Volatile Markers for Forecasting DryHop Aroma Intensity and Quality of Cascade and Centennial Hops. Brewing Science, 71(11-12), 116-140. https://doi.org/10.23763/ BrSc18-19lafontaine

Lafontaine, S., Varnum, S., Roland, A., Delpech, S., Dagan, L., Vollmer, D., Kishimoto, T., Shellhammer, T. (2019). Impact of Harvest Maturity on the Aroma Characteristics and Chemistry of Cascade Hops Used for Dry-Hopping. Food Chemistry, 278, 228-239. https://doi. org/10.1016/j.foodchem.2018.10.148

Lafontaine, S.R., Shellhammer, T.H. (2019a). How Hoppy Beer Production Has Redefined Hop Quality and a Discussion of Agricultural and Processing Strategies to Promote It. MBAA Technical Quarterly , 56(1), 1-12. https://doi.org/10.1094/tq-56-1-0221-01

Lafontaine, S.R., Shellhammer, T.H. (2019b). Investigating the Factors Impacting Aroma, Flavor, and Stability in Dry-Hopped Beers. MBAA Technical Quarterly, 56(1), 13-23. https://doi.org/10.1094/tq-561-0225-01

Lafontaine, S., Varnum, S., Roland, A., Delpech, S., Dagan, L., Vollmer, D., Kishimoto, T., Shellhammer, T. (2019). Impact of Harvest Maturity on the Aroma Characteristics and Chemistry of Cascade Hops Used for Dry-Hopping. Food Chemistry, 278, 228-239. https://doi. org/10.1016/j.foodchem.2018.10.148

Lermusieau, G., Bulens, M., Collin, S. (2001). Use of GC-Olfactometry to Identify the Hop Aromatic Compounds in Beer. Journal of Agricultural and Food Chemistry, 49(8), 3867-3874. https://doi.org/10.1021/ jf0101509

Lesschaeve, I., Noble, A.C. (2005). Polyphenols: Factors Influencing Their Sensory Properties and Their Effects on Food and Beverage Preferences. The American Journal of Clinical Nutrition, 81(1), 330S-335S. https://doi.org/10.1093/ajcn/81.1.330S

Lewis, M., Young, T. (2002). Brewing. Springer Science \& Business Media, pp. 408. ISBN-10: 0306472740; ISBN-13:|978-0306472749

Maye, J.P., Smith, R., Leker, J. (2016). Humulinone Formation in Hops and Hop Pellets and Its Implications for Dry Hopped Beers. MBAA Technical Quarterly, 53(1), 23-27. https://doi.org/10.1094/tq-531-0227-01

Meilgaard, M.C., Civile, G.V., Carr, T.B. (1999). Sensory Evaluation Techniques. New York: CRC Press, pp. 416. ISBN 9781003040729

Morcol, T.B., Matthews, P.D., Kennelly, E.J. (2021). Differences in Leaf Chemistry and Glandular Trichome Density between Wild Southwestern American Hop (Humulus neomexicanus) and Commercial Hop Cultivars. Journal of Agricultural and Food Chemistry, 69(27), 7798-7814. https://doi.org/10.1021/acs.jafc.1c02710

Naya, Y., Kotake, M. (1972). The Constituents of Hops (Humulus lupulus L.). VII. The Rapid Analysis of Volatile Components. Bulletin of the Chemical Society of Japan, 45(9), 2887-2891. https://doi. org/10.1246/bcsj.45.2887

Nielsen, T. (2009). Character Impact of Hop Aroma Compounds. In: T.H. Shellhammer (Ed.) Hop flavor and aroma : proceedings of the 1st International Brewers Symposium. St. Paul : American Society of Brewing Chemists. ISBN: 9780977051984

Oladokun, O., James, S., Cowley, T., Dehrmann, F., Smart, K., Hort, J., Cook, D. (2017). Perceived Bitterness Character of Beer in Relation to Hop Variety and the Impact of Hop Aroma. Food Chemistry, 230, 215-224. https://doi.org/10.1016/j.foodchem.2017.03.031
Oladokun, O., Tarrega, A., James, S., Cowley, T., Dehrmann, F., Smart, K., Cook, D., Hort, J. (2016). Modification of Perceived Beer Bitterness Intensity, Character and Temporal Profile by Hop Aroma Extract. Food Research International, 86, 104-111. https://doi.org/10.1016/j. foodres.2016.05.018

R-Core-Team (2020). R: A language and environment for statistical computing. R Foundation for Statistical Computing, Vienna, Austria. Retrieved from: https://www.R-project.org/

R Core Team (2021). R: A language and environment for statistical computing. R Foundation for Statistical Computing, Vienna, Austria. Retrieved from https://www.R-project.org/

Rettberg, N., Biendl, M., Garbe, L.A. (2018). Hop Aroma and Hoppy Beer Flavor: Chemical Backgrounds and Analytical Tools-A Review. Journal of the American Society of Brewing Chemists, 76(1), 1-20. https://doi.org/10.1080/03610470.2017.1402574

Roberts, M.T., Dufour, J.-P., Lewis, A.C. (2004). Application of Comprehensive Multidimensional Gas Chromatography Combined with Timeof-Flight Mass Spectrometry (GC $\times$ GC-TOFMS) for High Resolution Analysis of Hop Essential Oil. Journal of Separation Science, 27(5-6), 473-478. https://doi.org/10.1002/jssc.200301669

Sharp, D.C., Townsend, M.S., Qian, Y., Shellhammer, T.H. (2014). Effect of Harvest Maturity on the Chemical Composition of Cascade and Willamette Hops. Journal of the American Society of Brewing Chemists, 72(4), 231-238. https://doi.org/10.1094/ASBCJ-2014-1002-01

Ferreira, C.S., de Chanvalon, E.T., Bodart, E., Collin, S. (2018). Why Humulinones Are Key Bitter Constituents Only After Dry Hopping: Comparison With Other Belgian Styles. Journal of the American Society of Brewing Chemists, 76(4), 236-246. https://doi.org/10.1080/0361 0470.2018 .1503925

Takoi, K., Itoga, Y., Takayanagi, J., Matsumoto, I., Nakayama, Y. (2016). Control of Hop Aroma Impression of Beer with Blend-Hopping Using Geraniol-Rich Hop and New Hypothesis of Synergy among Hop-Derived Flavour Compounds. Brewing Science, 69(11-12), 85-93.

Takoi, K., Koie, K., Itoga Y., Katayama, Y., Shimase, M., Nakayama, Y., Watari, J. (2010). Biotransformation of Hop-Derived Monoterpene Alcohols by Lager Yeast and Their Contribution to the Flavor of Hopped Beer. Journal of Agricultural and Food Chemistry, 58(8), 5050-5058. https://doi.org/10.1021/jf1000524

Tielkemeier, Spencer. 2020. Exploring the World of 'Survivable' Compounds. Avaiblable from https://www.youtube.com/watch?v=SDIsUb2yyp0 [2020-09-09]

Ting, P.L., Ryder, D.S. (2017). The Bitter, Twisted Truth of the Hop: 50 Years of Hop Chemistry. Journal of the American Society of Brewing Chemists, 75(3), 161-180. https://doi.org/10.1094/ASBCJ-2017-3638-01

Tressl, R., Friese, L., Fendesack, F., Koeppler, H. (1978). Studies of the Volatile Composition of Hops during Storage. Journal of Agricultural and Food Chemistry, 26(6), 1426-1430. https://doi.org/10.1021/ jf60220a036

Vollmer, D.M, Shellhammer, T.H. (2016a). Dry Hopping on a Small Scale: Considerations for Achieving Reproducibility. MBAA Technical Quarterly, 53(3), 140-144. https://doi.org/10.1094/tq-53-3-0814-01

Vollmer, D.M., Shellhammer, T.H. (2016b). Influence of Hop Oil Content and Composition on Hop Aroma Intensity in Dry-Hopped Beer. Journal of the American Society of Brewing Chemists, 74(4), 242-249. https://doi.org/10.1094/ASBCJ-2016-4123-01

Vollmer, D.M., Shellhammer, T.H. (2016b). Influence of Hop Oil Content and Composition on Hop Aroma Intensity in Dry-Hopped Beer. Journal of the American Society of Brewing Chemists, 74(4), 242-2. 